\title{
ARE THERE DIFFERENCES BETWEEN MALE AND FEMALE BADMINTON ATHLETES IN SLEEP, PHYSICAL ACTIVITY AND SEDENTARY TIME?
}

\author{
EXISTEM DIFERENÇAS ENTRE ATLETAS DE BADMINTON MASCULINOS E FEMININOS NO SONO, \\ ATIVIDADE FISICA ETEMPO DE SEDENTARISMO?
}

\begin{abstract}
¿EXISTEN DIFERENCIAS ENTRE ATLETAS DE BASDMINTON MASCULINOS Y FEMENINOS EN EL SUEÑO, ACTIVIDAD FÍSICA Y TIEMPO DE SEDENTARISMO?
\end{abstract}

Arilene Maria da Silva Santos' ${ }^{1}$ (ID Physical Therapist)

Sérgio Luiz Galan Ribeiro' ${ }^{10}$ (Physical Education Professional) Antônio Valdeci Marreiro de Sousa Junior' (iD)

(Physical Education Professional) Dionis de Castro Dutra Machado' (Physical Therapist)

Paula Alves Monteiro 2 (ID

(Physical Education Professional) Pedro Moura' (ID)

(Physical Education Professional) Clarice Maria de Lucena Martins ${ }^{3}$ (iD (Physical Education Professional) Ismael Forte Freitas Junior ${ }^{4}$ (D) (Physical Education Professional) Marcos Antônio Pereira dos Santos ${ }^{5}$ (Physical Education Professional)

Fabrício Eduardo Rossi ${ }^{1,6}$ (iD) (Physical Education Professional)

1. Universidade Federal do Piauí (UFPI), Department of Physical Education, Immunometabolism of Skeletal Muscle and Exercise Research Group, Teresina, PI, Brazil. 2. Universidade Estadual de São

Paulo (UNESP), Faculdade de Ciências e Tecnologia, Department of Physical Education, Post-Graduation Program in Movement Sciences, Exercise and Immunometabolism Research Group, Presidente Prudente, SP, Brazil. 3. Universidade Federal da Paraíba (UFPB), Department of Physical Education, João Pessoa, PB, Brazil. 4. Universidade Estadual de São Paulo (UNESP), Department of Physical Education, Presidente Prudente, SP, Brazil.

5. Universidade Federal do Piauí, Campus Ministro Petrônio Portela,

Department of Biophysics and Physiology, Teresina, PI, Brazil. 6. Universidade Federal do Piauí (UFPI), Postgraduate Program in Health Sciences, Teresina, PI, Brazil.

\section{Correspondence:}

Fabrício Eduardo Rossi, Ph.D. Departamento de Educação Física, Universidade Federal do Piauí (UFPI). Campus Ministro Petrônio Portella, Ininga, Teresina, PI, Brasil. 64049-550.

fabriciorossi@ufpi.edu.br

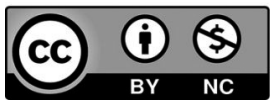

\begin{abstract}
Introduction: High-performance athletes often undergo periods of exhaustive training and insufficient recovery, which can lead to decreased performance, but it is not clear whether there are any differences between the sexes in the level of habitual physical activity, sedentary time or sleep quantity and quality in young highly trained badminton athletes. Objectives: The aim of this study was to compare the habitual physical activity (PA), sedentary time and sleep quantity and quality of highly trained young male and female badminton athletes and non-athletes. Methods: Twenty-seven young badminton athletes and twenty-one non-athletes (control group) were recruited. Sleep duration and quality (total time in bed, total sleep time, wake after sleep onset, sleep efficiency and latency), total counts, vigorous activity time and sedentary time were measured using a tri-axial accelerometer. Results: Male athletes spent less sedentary time $(p=0.028)$, more time in vigorous activity $(p=0.016)$ and had higher total counts $(p<0.001)$ than the male control group. There were no significant differences in sedentary time $(p=0.702)$ or vigorous activity time ( $p=0.205)$ between the female athletes and non-athletes, but the female athletes accumulated higher total counts than the female control group $(p=0.003)$. There were no significant differences between the sexes or groups for time in bed, total sleep time, sleep efficiency, wake after sleep onset and latency ( $p>0.05)$. Conclusion: Among males but not females, young highly trained badminton athletes had less sedentary time and more time in vigorous activity than the non-athletes, however, there were no significant differences between the sexes or groups in sleep quantity and quality. Level of evidence III; Case-control study.
\end{abstract}

Keywords: Racquet sports; Physical activity; Athletes.

\section{RESUMO}

Introdução: Atletas de alto rendimento com frequência são submetidos a períodos de treinamento exaustivo e recuperação insuficiente, o que pode levar à diminuição do desempenho, mas não está claro se há diferença entre os sexos quanto ao nivel de atividade física habitual, tempo sedentário, quantidade e qualidade do sono em jovens atletas de badminton altamente treinados. Objetivos: O objetivo deste estudo foi comparar a atividade física habitual (AF), o tempo de sedentarismo e a duração e qualidade do sono em jovens atletas de badminton altamente treinados e de não atletas, do sexo masculino e feminino. Métodos: Vinte e sete jovens atletas de badminton e vinte e um não atletas (grupo controle) foram recrutados. A duração e a qualidade do sono (tempo total na cama, tempo total de sono, vigília após o início do sono, eficiência e latência do sono), counts totais, tempo em atividade vigorosa e tempo de sedentarismo foram medidos com um acelerômetro triaxial. Resultados: Atletas do sexo masculino tiveram menos tempo de sedentarismo ( $p$ $=0,028)$, mais tempo de atividade vigorosa $(p=0,016)$ e maior quantidade de counts totais $(p<0,001)$ do que o grupo controle masculino. Não houve diferença significante no tempo de sedentarismo $(p=0,702)$ ou tempo de atividade vigorosa $(p=0,205)$ entre as atletas e não atletas, mas as atletas do sexo feminino acumularam maior quantidade de counts totais que o grupo controle feminino ( $p=0,003)$. Não houve diferença significante entre os sexos ou grupos para tempo na cama, tempo total de sono, eficiência do sono, vigília após o início do sono e latência $(p>0,05)$. Conclusões: Entre homens, mas não entre mulheres, os jovens atletas de badminton altamente treinados tiveram menor tempo de sedentarismo e maior tempo em atividades vigorosas do que os não atletas; entretanto, não houve diferença significante entre os sexos ou grupos na quantidade e qualidade do sono. Nível de evidência III; Estudo de caso controle.

Descritores: Esportes com raquete; Exercício físico; Atletas.

\section{RESUMEN}

Introducción: Los atletas de alto rendimiento con frecuencia son sometidos a periodos de entrenamiento exhaustivo y recuperación insuficiente, lo que puede llevar a una disminución del desempeño, pero no está claro si hay diferencia entre los sexos en cuanto al nivel de actividad física habitual, tiempo sedentario, cantidad y calidad del sueño en jóvenes 
atletas de bádminton altamente entrenados. Objetivos: El objetivo de este estudio fue comparar la actividad física habitual (AF), el tiempo de sedentarismo y la duración y calidad del sueño en jóvenes atletas de bádminton altamente entrenados y de no atletas, del sexo femenino y masculino. Métodos: Fueron reclutados veintisiete jóvenes atletas de bádminton y veintiuno no atletas (grupo control). La duración y la calidad del sueño (tiempo total en la cama, tiempo total de sueño, vigilia después del inicio del sueño, eficiencia y latencia del sueño), counts totales, el tiempo en actividad vigorosa y el tiempo de sedentarismo fueron medidos con un acelerómetro triaxial. . Resultados: Los atletas del sexo masculino tuvieron menos tiempo de sedentarismo $(p=0,028)$, más tiempo de actividad vigorosa $(p=0,016)$ y mayor cantidad de counts totales $(p<0,001)$ que el grupo control masculino. No hubo diferencias significativas en el tiempo de sedentarismo ( $p=0,702)$ o tiempo de actividad vigorosa $(p=0,205)$, entre las atletas y no atletas, pero las atletas del sexo femenino acumularon mayor cantidad de counts totales que el grupo control femenino $(p=0,003)$. No hubo diferencias significativas entre los sexos o grupos para tiempo en la cama, tiempo total de sueño, eficiencia del sueño, vigilia después del inicio del sueño y latencia ( $p>0,05)$. Conclusiones: Entre hombres, pero no entre mujeres, los jóvenes atletas de bádminton altamente entrenados tuvieron menor tiempo de sedentarismo y mayor tiempo en actividades vigorosas que los no atletas; entretanto, no hubo diferencia significativa entre los sexos o grupos en la cantidad y calidad del sueño. Nivel de evidencia III; Estudio de caso control.

Descriptores: Deportes de raqueta; Ejercicio físico; Atletas.

\section{INTRODUCTION}

Morphological, physiological, and cognitive functions have assumed an important role in obtaining better results in high-performance athletes. These athletes are often submitted to periods of exhaustive training and insufficient recovery, which can lead to a performance decrease. ' Although athletes often perform high intensity daily training routines and accomplished the moderate-to-vigorous PA recommendation (>150 min/week), according to ACSM, when sedentary time ( $<1.5 \mathrm{METs}$ ) is considerate, which it is characterized by low energy expenditure (i.e. watching television), they presented an amount of sedentary time similar to those who did not comply with the recommendation. ${ }^{2}$ Weiler et al. $(2015)^{3}$ observed that $79 \%$ of the daily routine of English first division professional footballer players was characterized by sedentary activities. Furthermore, sedentary behavior is associated with weight gain, an increased risk of cardiovascular diseases, type II diabetes, and an increased risk of early mortality. ${ }^{2,4}$ Therefore, complying with the daily PA recommendations, as well as decreasing sedentary time are essential in any population and age group, especially athletes, whose activities beyond the training period correspond to approximately $80 \%$ of their routine and are critical for athlete recovery. ${ }^{5}$

Among recovery strategies, sleep has huge importance, since it allows maintenance of an alertness status, contributes to a shorter reaction time, and improves mood and physical vigor., ${ }^{6,7}$ Leeder et al. $(2012)^{8}$ compared olympic athletes from different modalities with non-athletes from college and observed lower sleep quality in athletes and also significant difference between markers of sleep efficiency between genders. Despite middle-aged and elderly female populations report poorer subjective sleep quality than men of similar age,, 10 when analyzed the objective polysomnographic (PSG) measures, there are different results, since female have better sleep quality than male. Goel et al. (2005) ${ }^{11}$ compared 16 men and 15 women, ages 18 to $30 \mathrm{yr}$ across 3 consecutive overnight sessions and verified a higher sleep time, shorter total time awake and latencies to sleep onset and greater sleep efficiency in female than male.

Regarding the gender differences in PA levels, several studies at the literature have been shown that boys were more physically active than girls, 12,13 however, it is not clear if there is difference between gender on habitual PA level, sedentary time and sleep quantity and quality in high-trained young badminton athletes. The present study would be important for coaches and sports physiologists understand about the daily routine of athletes, which could help them with goal-setting and improve their exercise prescription and recovery strategy.

Thus, the aim of this study was to compare the PA levels, sedentary time and sleep duration and quality in high-trained young badminton athletes according to gender and non-athletes. The hypothesis of this study were that male athletes would present better sleep quality, as well as lesser sedentary time and greater habitual practice of physical activity in relation to female, furthermore, athletes would show greater sleep quality, lesser sedentary time and higher time in vigorous activity and total counts than physically active non-athletes.

\section{METHODS}

\section{Subjects}

The sample consisted of 27 young badminton athletes, 16 men (age $=17.5 \pm 1.6$ years, total body mass $=69.6 \pm 10.1 \mathrm{~kg}$ ), and 11 women (age $=19.1 \pm 4.1$ years, total body weight $=56.5 \pm 8.0 \mathrm{~kg}$ ). The inclusion criteria in the study were: being over 15 years old at the date of collection; not presenting injuries during the evaluation period; performing the daily training routine during the evaluation week; and signing the informed consent form.

The sample was recruited for convenience through contact with coaches of the Brazilian Badminton Confederation. All athletes were experienced in badminton ( $9.6 \pm 3.6$ years), and frequently participated in national and international competitions. Assessments were performed during the preseason (January 2019), when athletes trained 5 times per week (approximately 4 hours per day, two sessions - morning and afternoon). All athletes were residing in the same city of the control group during this study.

The control group included 21 volunteers non-athletes, 11 men (age $=21.5 \pm 2.5$ years, total body mass $=60.7 \pm 5.1 \mathrm{~kg}$ ), and $10 \mathrm{wo}-$ men (age $=20.1 \pm 1.6$ years, total body weight $=54.0 \pm 9.1 \mathrm{~kg}$ ) from a university population, who was participating in an resistance training program in the last three months ( 3 times per week and 60 minutes per day). All participants or guardians (when age $<18$ years) signed a consent form and were informed about the purpose of the study. Protocols were developed according to the Declaration of Helsink 2013 and approved by the research ethics committee of the Federal University of Piauí (protocol: 2.555.506). 


\section{Procedures}

Accelerometer - Habitual physical activity and sedentary time assessment

Actigraph GT3X+ accelerometers (ActiGraph, Pensacola FL, United States) were used to monitor physical activity and sleep. Participants were encouraged to wear the accelerometer in their dominant wrist for 7 consecutive days, removing it only during showering or swimming time. The minimal amount of accelerometer data considered acceptable for analytical purposes were at least 4 days (3 weekdays and 1 weekend day), with a minimum of $20 \mathrm{~h}$ per day. Data were collected at a sampling rate of $100 \mathrm{~Hz}$, downloaded as raw data and processed as 10-sec epochs. Cut-points between 0 to 275 counts per 5 seconds were defined as sedentary time, $\geq 778$ counts per 5 seconds was defined as vigorous, according validated methods suggested by Crouter et al. (2015) ${ }^{14}$ for analyzing dominant wrist accelerometer data in youth, and total counts in minutes per day was recorded, since there are no specific cut-points for badminton players to our knowledge.

\section{Sleep parameters}

Participants were encouraged to wear the accelerometer in their dominant wrist for 7 consecutive days and free-living sleep was analyzed by 1 -min counts. The devices contain motion-sensitive accelerometers which have been previously validated for objective sleep measurement. ${ }^{15}$ Rest and sleep periods were automatically identified using the Actilife software from Actigraph (Pensacola, FL, USA) (version 6.13.0.), as well as through a hand-written sleep diary that each subject kept. The following parameters were reported for each sleep event over the 7-day period using the Actilife software: total in bed (hour per day), total sleep time (hour per day), wake after sleep onset (minutes per day), efficiency (\%) and latency (minutes per day).

\section{Statistical analysis}

The Shapiro-Wilk test was used to verify the normality of the data set and where these were not normally distributed, the data are presented as median and inter-quartile range and the Mann-Whitney test was performed. When normal distribution was confirmed, the data are shown as mean and standard deviation and the Independent Student $\mathrm{t}$ test was conducted. Statistical significance was set at $\mathrm{p}<0.05$. The data were analyzed using the Statistical Package for Social Sciences 17.0 (SPSS Inc. Chicago. IL. USA).

\section{RESULTS}

All participants who received accelerometers provided valid data and were included in analyses. The Figure 1 shows the comparison between gender and groups on the sedentary time, time in vigorous activity and total counts.

Male athletes showed lower sedentary time, (Figure 1A) higher time in vigorous activity (Figure 1B) and total counts (Figure 1C) than male control, however, there were no significant difference between female athletes and non-athletes in the sedentary time and time in vigorous but they accumulated higher total counts than female control (Figure 1C).

There were no significant differences between male and female athletes or male and female control for sedentary time, time in vigorous and total counts ( $p>0.05)$.

The Figure 2 presents the comparison between gender and groups on the sleep quantity and quality.

There were no significant differences between gender and groups for time in bed, (Figure 2A) total sleep time, (Figure 2B) sleep efficiency, (Figure 2C) wake after sleep onset (Figure 2D) and latency (Figure 2E).

There were no significant differences between male and female athletes or male and female control for sleep quantity and quality.
A

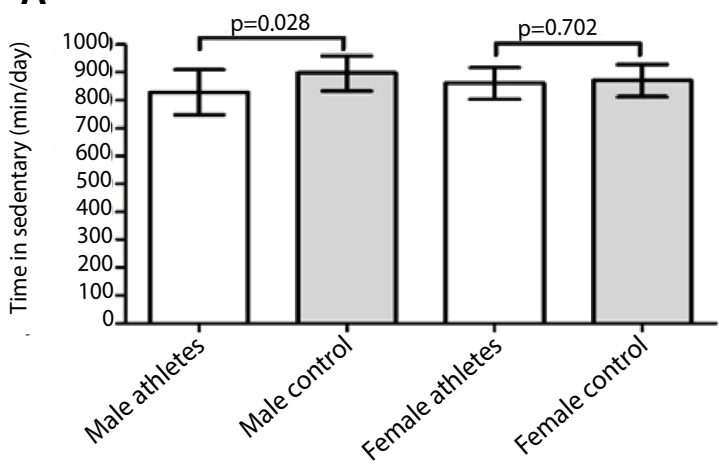

B

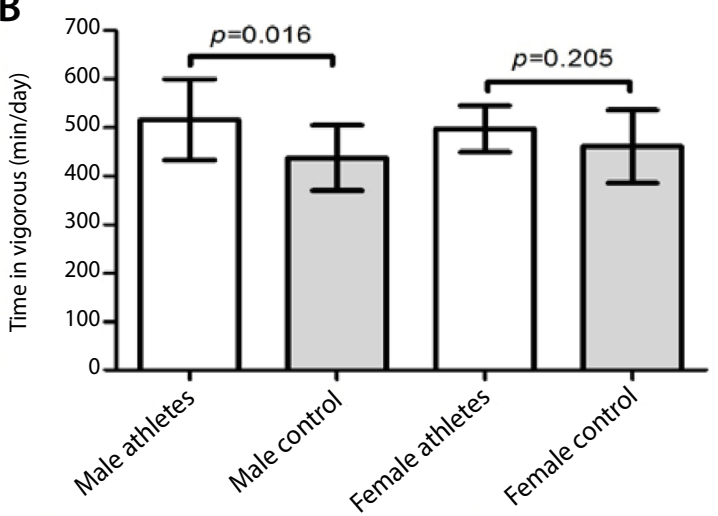

C

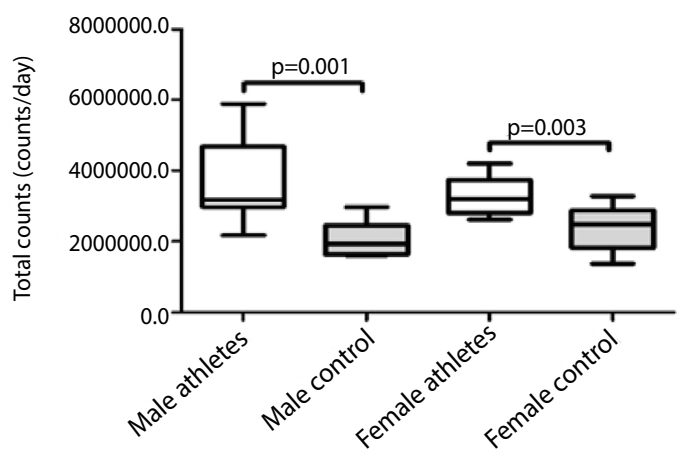

Figure 1. Comparison between gender and groups on the sedentary time, time in vigorous activity and total counts.

\section{DISCUSSION}

The objective of the present study was to compare the PA levels, sedentary time and sleep quantity and quality in high-trained young badminton athletes according to gender and non-athletes. Our main results showed that male but not female high-trained young badminton athletes accumulated lower sedentary time and higher time in vigorous activity in relation to non-athletes physically active. There were no significant difference between gender and groups on the sleep quantity and quality.

In a recent study conducted by Wang et al. (2019) ${ }^{12}$ in Taiwanese adolescents using an accelerometer, it was observed that men had less sedentary time and greater habitual physical activity levels than women. In concordance, Ishii et al. (2015) ${ }^{13}$ compared also objectively sedentary time and physical activity but in younger adolescents (3-15 years) and observed that boys were more physically active and took more steps/ day than girls. In the present study, there were no significant differences in the sedentary time, PA levels and total counts between male and 


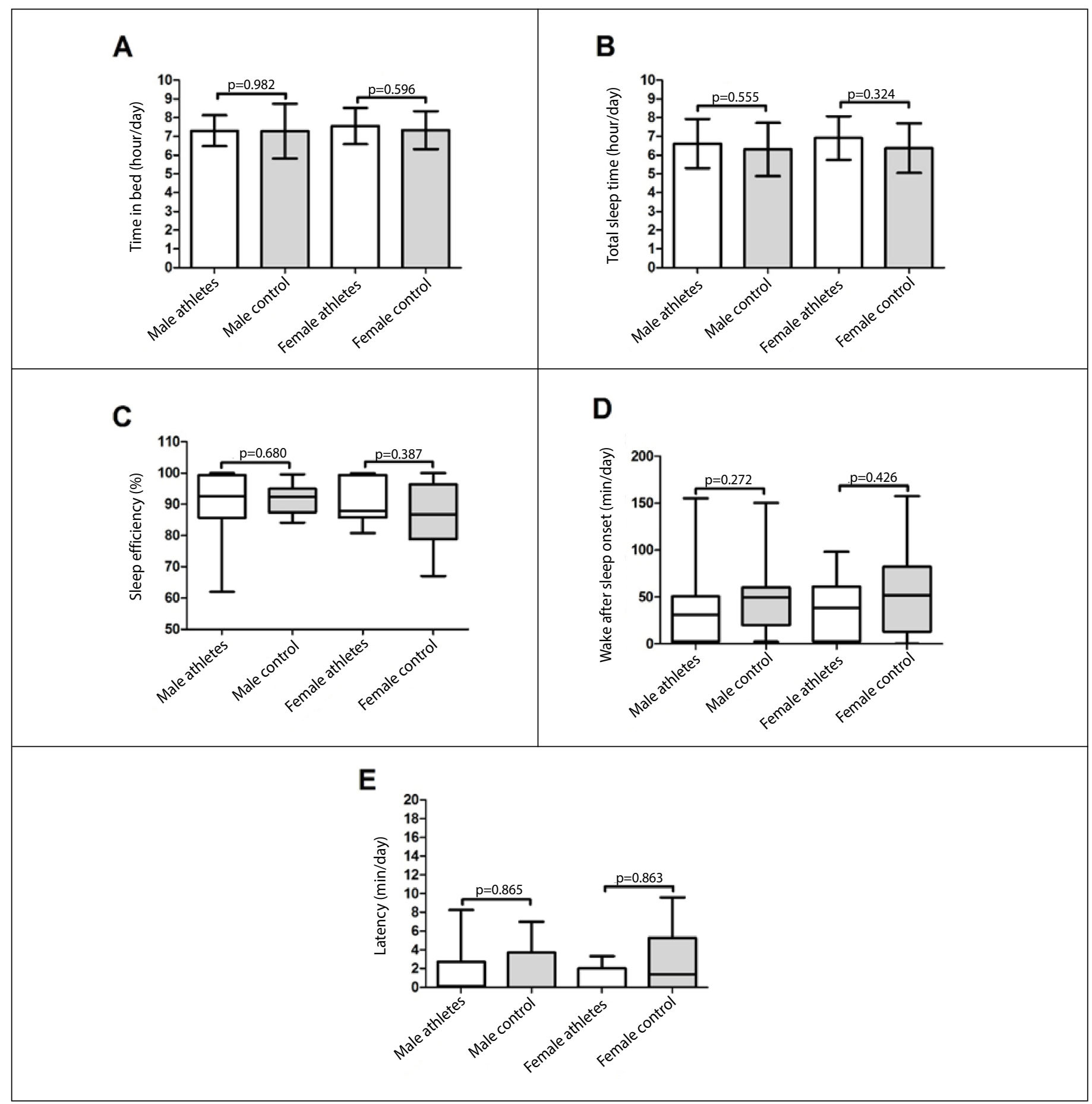

Figure 2. Comparison between gender and groups on the sleep quantity and quality.

female athletes. These findings differ from our results, possibly due we analyzed high-trained athletes undergoing the pre-season training routine, therefore they were engaged in activities with greater energy expenditure, which could eliminated social influences and perceived societal norms where the participation of girls in physical activity can be influenced mainly during adolescent, ${ }^{16}$ however, this hypothesis should be investigate in athletes.

In the present study, there were no significant difference in the sedentary time between female athletes and non-athletes. Although we did not find significant difference within group, we believe that female non-athletes accumulated higher sedentary time than male non-athletes. Anjos et al. (2012) 17 $^{17}$ analyzed PA in 1689 subjects of different age and both gender via 24-hour recall, and found that men accumulated greater moderate to vigorous activity during leisure activities and the women during domestic activities, however despite activities of daily living promote increased energy expenditure, the intensity of these activities is generally mild (<3 METs). Furthermore, sedentary time is strongly related to metabolic risk, independent of physical activity, ${ }^{18}$ therefore, to decrease sedentary time is essential in any population and age group.

Regarding the sleep parameters, we did not find significant differences between genders and groups. In opposite, Kawasaki et al. (2019)19 assessed the subjective quality of sleep measured by the Pittsburgh Sleep Quality Index in athletes from different sports and verified that females had poorer subjective sleep quality than males, which can be explained by difference between sex hormones, ${ }^{20}$ as well as stress factors, such as family conflicts and a higher incidence of depression can negatively impact the woman's sleep. ${ }^{21}$ In elite athletes, Leeder et al. $(2012)^{8}$ observed lower sleep quality in athletes compared to non-athletes 
recruited from college, however, they found greater sleep efficiency in female compared to male. The finding that males spend more time in bed than females but similar amount of total sleep, potentially suggests an adaptive response by males to achieve the same amount of actual sleep due to their poorer sleep efficiency.

In addition, Goel et al. (2005) ${ }^{11}$ compared 16 men and 15 women with age between 18 to 30 y across 3 consecutive overnight sessions in polysomnographicand and demonstrated a higher sleep time, shorter total time awake and latencies to sleep onset and greater sleep efficiency in female than male. Although we have recruited similar control group that Leeder's study et al. (2012), ${ }^{8}$ the student's routine could have impaired the quality of sleep during data colleting period, furthermore, the difference between status of training can be influence the sleep response, once we measured high-trained athletes but they were no Olympic level like as analyzed by Leeder and colleagues (2012). ${ }^{8}$

Despite the importance of the present study for coaches regarding the daily routine of athletes, which could help them with goal-setting and improve their exercise prescription, some limitations should be mentioned, such as, the convenience sample; there was a small sample size; there are no specific cut-points for badminton players to our knowledge and only young athletes were evaluated. In addition, no technical or tactical performance analyses were carried out. However, it is necessary to highlight that we intended to recruit non-athletes who were engaged in an exercise program, thus they were physically active. Therefore, future longitudinal studies should be conducted to investigate the influence of sedentary time on physical fitness, body composition and performance in different type of athletes, according gender and age.

\section{CONCLUSION}

The present study showed that male but not female high-trained young badminton athletes presented lower sedentary time and higher time in vigorous activity than non-athletes physically active, however, there were no difference between genders and groups in the sleep quantity and quality.

\section{ACKNOWLEDGMENTS}

We thank Dr. Kong Chen for the use of the accelerometers (funded by NIH Z01 DK071013).

Funding: the authors would like to thank FAPEPI for their support (FAPEPI / MCT/ CNPq No 007/2018).

All authors declare no potential conflict of interest related to this article

AUTHORS' CONTRIBUTIONS: All authors made significant individual contributions to the manuscript. AMSS, SLGR, AVMSJ, DCDM: Data collection, data analysis and interpretation, drafting the article and/or its critical revision, final approval of the version to be published. PAM, PM*, CMLM, IFFJ, MAPS: Data analysis and interpretation, drafting the article and/or its critical revision, final approval of the version to be published. FER: Conception and design of the study, data collection, data analysis and interpretation, drafting the article and/or its critical revision, final approval of the version to be published.

\section{REFERENCES}

1. Silva LPOD, Oliveira MFMD, Caputo F. Métodos de recuperação pós-exercício. Rev Educ Fis. 2013;24(3):489-508,

2. Exel J, Mateus N, Travassos B, Gonçalves B, Gomes I, Leite N, et al. Off-training levels of physical activity and sedentary behavior in young athletes: Preliminary results during a typical week. Sports (Basel). 2018;6(4):141.

3. Weiler R, Aggio D, Hamer M, Taylor T, Kumar B. Sedentary behaviour among elite professional footballers: health and performance implications. BMJ Open Sport Exerc Med. 2015;1(1):e000023.

4. Ekelund U, Steene-Johannessen J, Brown WJ, Fagerland MW, Owen N, Powell KE, et al. Does physical activity attenuate, or even eliminate, the detrimental association of sitting time with mortality? A harmonised meta-analysis of data from more than 1 million men and women. Lancet. 2016;388(10051):1302-10.

5. Sperlich B, Becker M, Hotho A, Wallmann-Sperlich B, Sareban M, Winkert K, et al. Sedentary behavior among national elite rowers during off-training - a pilot study. Front Physiol. 2017;8:655.

6. Bleyer FTDS, Andrade RD, Teixeira CS, Felden ÉPG. Sono e treinamento em atletas de elite do Estado de Santa Catarina, Brasil. Rev Bras Educ Fís Esporte. 2015;29(2):207-16.

7. Mah CD, Mah KE, Kezirian EJ, Dement WC. The effects of sleep extension on the athletic performance of collegiate basketball players. Sleep. 2011;34(7):943-50.

8. Leeder J, Glaister M, Pizzoferro K, Dawson J, Pedlar C. Sleep duration and quality in elite athletes measured using wristwatch actigraphy. J Sports Sci. 2012;30(6):541-5.

9. Li RHY, Wing YK, Ho SC, Fong SYY. Gender differences in insomnia-a study in the Hong Kong Chinese population. J Psychosom Res. 2002;53(1):601-9.

10. Voderholzer U, Al-Shajlawi A, Weske G, Feige B, Riemann, D. Are there gender differences in objec tive and subjective sleep measures? A study of insomniacs and healthy controls. Depress. Anxiety. 2003;17(3):162-72.
11. Goel N, Kim H, Lao RP. Gender differences in polysomnographic sleep in young healthy sleepers. Chronobiol Int. 2005;22(5):905-15

12. Wang W-Y, Hsieh Y-L, Hsueh M-C, Liu Y, Liao Y. Accelerometer-Measured Physical Activity and Sedentary Behavior Patterns in Taiwanese Adolescents. Int J Environ Res Public Health. 2019;16(22):4392.

13. Ishii K, Shibata A, Adachi M, Nonoue K, Oka K. Gender and grade differences in objectively measured physical activity and sedentary behavior patterns among Japanese children and adolescents: a crosssectional study. BMC Public Health. 2015;15(1):1254.

14. Crouter SE, Flynn JI, Bassett Jr DR. Estimating physical activity in youth using a wrist accelerometer. Med Sci Sports Exerc. 2015;47(5):944-51

15. Slater JA, Botsis T, Walsh J, King S, Straker LM, Eastwood PR. Assessing sleep using hip and wrist actigraphy. Sleep Biol Rhythms. 2015;13(2):172-80.

16. Whitehead S, Biddle S. Adolescent girls' perceptions of physical activity: A focus group study. Eur Phy Educ Rev. 2008;14(2):243-62.

17. Anjos LA, Barbosa TB, Wahrlich V, Vasconcellos MT. Patterns of physical activity during a typical day for adults in Niteroi, Rio de Janeiro State, Brazil: the Nutrition, Physical Activity, and Health Survey (PNAFS). Cad Saúde Pública. 2012;28(10):1893-902.

18. Bankoski A, Harris TB, McClain JJ, Brychta RJ, Caserotti P, Chen KY, et al. Sedentary activity associated with metabolic syndrome independent of physical activity. Diabetes Care. 2011;34(2):497-503.

19. Kawasaki Y, Kasai T, Koikawa N, Hanazato N, Suda S, Murata A, et al. Sex differences in factors associated with poor subjective sleep quality in athletes. J Sports Med Phys Fitness. 2019;60(1):140-51.

20. Neumann N, Lotze M, Domin M. Sex-specific association of poor sleep quality with gray matter volume. Sleep. 2020;43(9):zsaa035.

21. Moreno CRC, Santos JLF, Lebrão ML, Ulhôa MA, Duarte YAO. Problemas de sono em idosos estão associados a sexo feminino, dor e incontinência urinária. Rev Bras Epidemiol. 2018;21(2):e180018. 